\title{
PERANCANGAN SISTEM PENGAMANAN RUANGAN \\ BERBASIS MIKROKONTROLER (ARDUINO) DENGAN METODE MOTION DETECTION
}

\author{
${ }^{1)}$ Anip Febtriko, ${ }^{2)}$ Tatang Sofian \\ Jurusan Teknik Informatika, FakultTeknik,Universitas Abdurrab \\ Jl. Riau Ujung no.73 Pekanbaru \\ E-mail: aniep_febtric@yahoo.com,tatang.sofian@yahoo.com
}

\begin{abstract}
ABSTRAK
Keamanan merupakan hal yang sangat mutlak diinginkan oleh setiap orang. Dengan adanya rasa aman maka orang tidak akan merasa khawatir.Untuk itu diperlukan suatu informasi keamanan yang cepat dan efektif agar pegawai sekuriti dapat langsung mengetahui informasi apabila ada tindakan pencurian pada ruangan yang di amankan. Pada proyek akhir ini dibahas tentang suatu sistem keamanan ruangan yang dilengkapi sensor PIR yang dipasang pada pintu masuk suatu ruangan maupun pada titik yang dianggap penting untuk diberi sistem keamanan. sensor passive infrared akan dipasang di pintu ruangan, kemudian sebagai pemrosesnya digunakan mikrokontroller Arduino. Kemudian untuk menginformasikan menggunakan led sebagai indikator, buzzer sebagai sirine peringatan dan lcd sebagai penampil teks notifikasi keadaan. Sistem ini cara kerjanya yaitu sensor PIR akan mendeteksi adanya keberadaan orang atau tidak pada ruangan yang diberi sistem keamaan ini, selanjutnya oleh mikrokontroller Arduino akan memproses datanya untuk memerintahkan agar alarm berbunyi serta memberikan notifikasi pada lcd bahwa adanya pergerakan pada ruangan . Passive infrared Receiver yang digunakan adalah sensor PIR KC778 R kemudian range sensor PIR yang digunakan pada sistem mempunyai range maksimal 60 .
\end{abstract}

Kata Kunci: sensor pir, mikrokontroller, alarm, sistem keamanan

\section{ABSTRACT}

Safety is something that is absolutely desired by everyone. With their sense of security then people will not feel it necessary khawatir. Untuk a security information quickly and effectively so that employees can immediately know the security information if there is theft in the room is secured. At the end of the project is discussed about a security system that is equipped with PIR sensor mounted at the entrance to a room or at the point considered vital given the security system. passive infrared sensor will be installed on the door of the room, then as pemrosesnya use Arduino microcontroller. Then to inform use as an indicator LED, buzzer as a siren warning and notification text viewer LCD as a state. The system is the way it works is the PIR sensor will detect the presence or not in the room who were given this system's security, then the Arduino microcontroller will process the data to instruct the alarm to sound and provide notification on lcd that their movement in the room. Passive infrared receiver is used $P I R$ sensor KC778 R then range PIR sensor used in the system has a maximum range of 60.

Keywords : pir sensor, microcontroller, alarm, security systems

\section{PENDAHULUAN}

Uang dalam jumlah besar atau benda-benda berharga lainnya seperti emas, intan atau berlian biasanya disimpan di tempat-tempat tertentu dengan sistem pengaman yang lebih dari biasa. Misalnya di dalam brankas yang memiliki sistem kunci dengan sejumlah kombinasi angka. Brankas ini ditempatkan didalam ruangan dengan sistem pengaman tertentu, dan gedung yang dijaga oleh beberapa pegawai sekuriti. Namun seiring dengan perkembangan teknologi, modus pencurian barang-barang berharga juga terus berkembang. Oleh sebab itu diperlukan upaya untuk terus meningkatkan teknologi system pengaman ruangan.

Perkembangan ilmu pengetahuan dan teknologi, terutama dibidang 
Elektronika dan Informatika, diharapkan dapat meningkatkan teknologi system

pengaman ruangan tersebut. Sejumlah sistem pengaman ruangan telah diciptakan antara lain dengan menggunakan detektor sinyal laser dengan keluaran berupa bunyi alarm, atau dengan kamera CCTV yang dipantau melalui TV diruangan sekuriti

Kedua sistem pengaman ruangan ini memiliki kelemahan. Sinar laser dapat terlihat bila mengenai partikel-partikel debu dan asap rokok. Sedangkan kamera CCTV juga mudah diketahui keberadaannya 2 karena berukuran relatif besar dan biasanya bergerak/berputar dalam rentang sudut tertentu. Hal ini sering kali mudah diatasi oleh pencuri profesional. Selain itu, kamera cctv juga tidak dapat berfungsi saat ruangan dalam keadaan gelap. Kelemahankelemahan sistem pengaman ruangan tersebut diatas memunculkan ide untuk merancang suatu prototipe untuk meningkatkan sistem pengaman ruangan berdasarkan radiasi inframerah objek yang berada di suatu ruangan. Sensor yang digunakan adalah PIR (Passive Infrared Receiver) dan sinyal keluarannya diolah oleh mikrokontroler kemudian mengaktifkan alarm untuk mengeluarkan suara peringatan yang berada pada ruangan.

PIR (Passive Infrared Receiver) adalah sebuah sensor yang menangkap pancaran sinyal inframerah yang dikeluarkan oleh tubuh manusia. Sensor PIR (Passive Infrared Receiver) dapat merespon perubahan perubahan pancaran sinyal inframerah yang dipancarkan oleh tubuh manusia, pancaran sinyal inframerah ditubuh manusia dengan panjang gelombang 9,4 $\mu \mathrm{m}$. Sensor PIR (Passive Infrared Receiver) terbuat dari bahan kristal yang akan menimbulkan beban listrik ketika terkena panas dan pancaran sinyal inframerah.

\section{Rumusan Masalah}

Pembahasan masalah dalam laporan tugas akhir ini hanya mencakup masalah-masalah sebagai berikut:

1. Bagaimana cara mengimplementasikan sensor PIR dalam perancangan sistem keamanan ruangan?

2. Bagaimanakah cara kerja mikrokontroler pada Arduino?

\section{Batasan Masalah}

Dikarenakan luasnya permasalahan di dalam pembahasan dan agar tidak terjadi kesalah pahaman maksud dari apa yang ada di dalam penulisan tugas akhir ini maka dibutuhkannya pembatasan masalah tersebut antara lain:

1. Sensor PIR tidak digunakan untuk mengukur jarak tapi hanya untuk mendeteksi adanya objek yang bergerak dan memancarkan inframerah.

2. Pengujian alat dilakukan diruangan .

3. Pengujian alat dilakukan pada pintu masuk suatu ruangan dan pada titik suatu ruangan yang dianggap penting memiliki sistem keamanan.

\section{Tujuan Penulisan}

1. Sebagai pengaplikasian ilmu pengetahuan yang diperoleh dari perkuliahan terhadap kehidupan sehari hari.

2. Pengembangan ilmu kreatifitas mahasiswa dalam bidang ilmu Elektronika dan Informatika.

3. Merancang dan mengetahui cara kerja sensor PIR dengan pengendali Mikrokontroler Arduino. 
Dengan menggunakan sensor PIR yang mampu mendeteksi inframerah yang dipancarkan tubuh manusia, maka hasil penelitian ini diharapkan dapat menjadi alternatif untuk peningkatan sistem keamanan ruangan dari tindak kejahatan seperti pencurian.

\section{METODE}

\section{Identifikasi Masalah}

Identifikasi masalah adalah tahap awal dari penelitian penyusunan ini. Masalah yang di identifikasi adalah sebagai berikut :

a. Maraknya kejahatan seperti tindak pencurian. Dengan adanya teknologi system keamanan sekarang, yang memiliki kelemahan masing masing dan harga yang relatif mahal, timbulah ide untuk merancang suatu sistem keamaanan ruangan yang menggunakan PIR .

b. Kebutuhan sistem yang dibutuhkan dalam perancangan sistem keamanan ruangan berbasis mikrokontroler (Arduino) dengan metode motion detections.

\section{Studi Pustaka}

Studi pustaka dilakukan untuk memperoleh teori teori dasar yang dibutuhkan sehingga dapat digunakan sebagai acuan dalam menyelesaikan penelitian ini yang meliputi Mikrokontroler, Pemograman Arduino, dan Elektronika Dasar, antara lain dengan cara berikut :

a. Literatur dari beberapa website yang mendukung penelitian ini.

b. Buku buku baik hardcopy ataupun softcopy

c. Jurnal jurnal softcopy yang mendukung penelitian ini.

\section{Analisa Sistem}

Mencari semua kebutuhan yang diperlukan dalam merancang system keamanan dengan metode Motion Detections antara lain melingkupi hal hal sebagai berikut :

a. Melakukan analisa perangkat keras yang dapat digunakan dan mudah di dapatkan di pasaran.

b. Analisa perangkat lunak yang akan digunakan dalam perancangan sistem , sehingga hasil dapat dicapai dengan rumusan masalah.

\section{Perancangan Sistem}

Perancangan sistem dilakukan sebagai langkah awal sebelum terbentuknya suatu sistem beserta rangkaian elektronik pendukungnya yang siap untuk direalisasikan. Hal ini dilakukan agar sistem yang dibuat dapat berjalan sebagaimana mestinya.

1. Diagram Blok Rangkaian

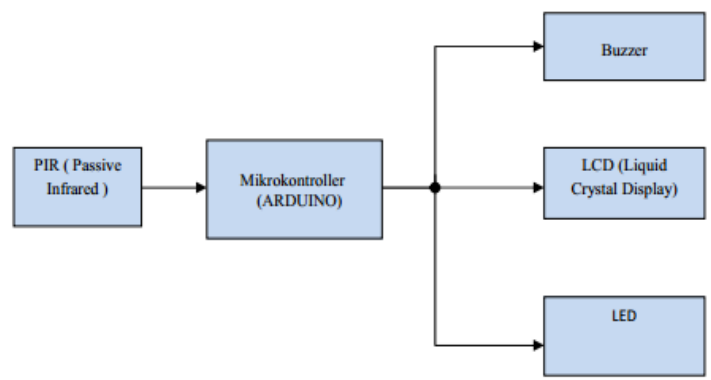

Gambar 1. Diagram Blok Rangkaian

2. Skema Rangkaian Sistem

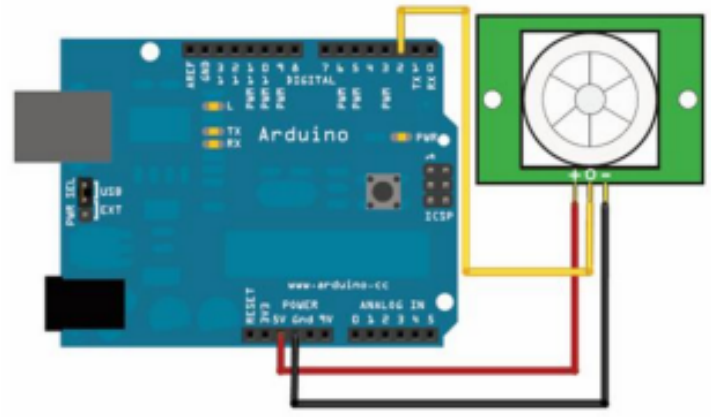

Gambar 2. Rangkaian Arduino dan PIR 


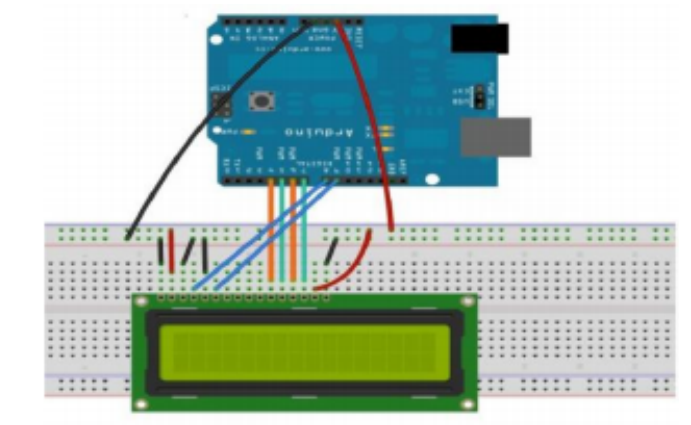

Gambar 3. Arduino dengan LCD $16 \times 2$

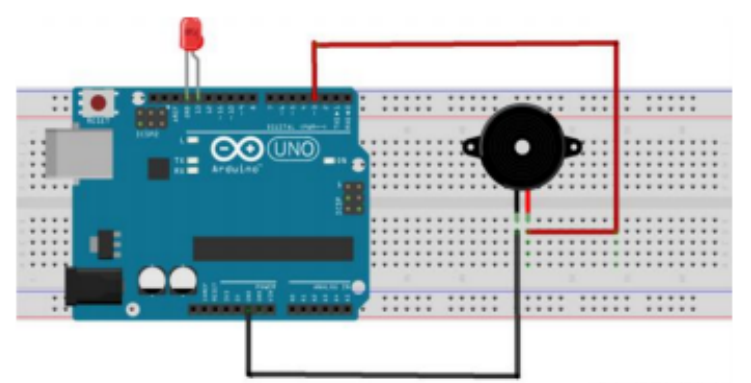

Gambar 4. Arduino dengan Led dan Buzzer

\section{Pembuatan Sistem}

Tahap pembuatan sistem yang dimaksud adalah pemasangan komponen komponen elektronika pada Arduino, kemudian dilakukan penggabungan dari tiaptiap blok tadi menjadi satu blok rangkaian sesuai dengan perencanaan. Pada tahap ini juga pembuatan perangkat lunak dilakukan dengan mengimplementasikan diagram alir dari program yang telah direncanakan, penulisan program dalam bahasa Arduino dengan menggunakan IDE Arduino yang nantinya dikonversikan dalam bahasa mesin.

\section{Pengujian Alat}

Metode pengujian yang dilakukan adalah menguji sistem untuk tiap-tiap blok rangkaian, menguji sistem secara menyeluruh, kemudian menganalisa dari setiap hasil pengujian baik pengujian tiap blok maupun pengujian sistem secara keseluruhan, dapat dilihat alat dan bahan dibawah ini :

Tabel 1. Alat dan Bahan

\begin{tabular}{|l|l|}
\hline \multicolumn{1}{|c|}{ Hardware } & \multicolumn{1}{|c|}{ Software } \\
\hline Arduino UNO R3 & Software Arduino 1.0.5 \\
PIR (Passive Infrared) & Software fritzing \\
LED & OS Windows 7 \\
LCD M1632 16 x 2 & OS Elementary Linux \\
Protoboard & \\
Potentiometer & \\
Kabel Jumper & \\
Piezo Buzzer & \\
Tools & \\
\hline
\end{tabular}

\section{HASIL}

1. Rancangan Perangkat keras (Hardware)

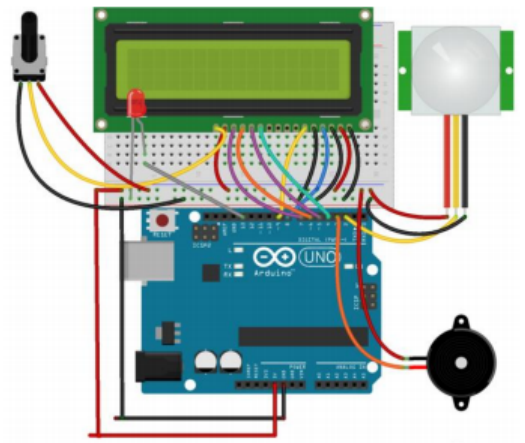

Gambar 5. Rancangan Alat secara keseluruhan

Tabel 2. Penggunaan PinArduino

\begin{tabular}{|c|l|}
\hline $\begin{array}{c}\text { Arduino } \\
\text { Pin }\end{array}$ & \multicolumn{1}{|c|}{ Keterangan } \\
\hline 2 & Pin Vout pada pir \\
\hline 3 & Pin pada buzzer \\
\hline 4 & Pin 11 pada led yang merupakan pin D4 (Data Bus 4) \\
\hline 5 & Pin 12 pada led yang merupakan pin D4 (Data Bus 5) \\
\hline 6 & Pin 13 pada led yang merupakan pin D4 (Data Bus 6) \\
\hline 7 & Pin 14 pada led yang merupakan pin D7 (Data Bus 7) \\
\hline 8 & Pin 4 pada lod yang merupakan pin RS (Register Select) \\
\hline 9 & Pin 6 pada lod yang merupakan pin E (Enable clock LCD) \\
\hline 13 & Pin anoda (+) pada led yg berfungsi sebagai output \\
\hline $5 \mathrm{~V}$ & $\begin{array}{l}\text { Berfungsi sebagai untuk power mikrokontroller dan } \\
\text { komponen lainnya }\end{array}$ \\
\hline GND & Berfungsi sebagai jalur ground arduino dan komponen lain \\
\hline
\end{tabular}




\section{Pengujian Arduino uno}

Proses ini adalah pengujian pada mikrokontroler arduino uno yang bertujuan untuk memastikan apakah arduino uno dapat berjalan dengan baik dan

dapat digunakan pada proyek tugas akhir ini. Driver arduino telah terinstal sebelum nya pada sistem operasi yang digunakan. Papan arduino terkoneksi ke usb port yang ada pada komputer dengan menggunakan kabel usb.

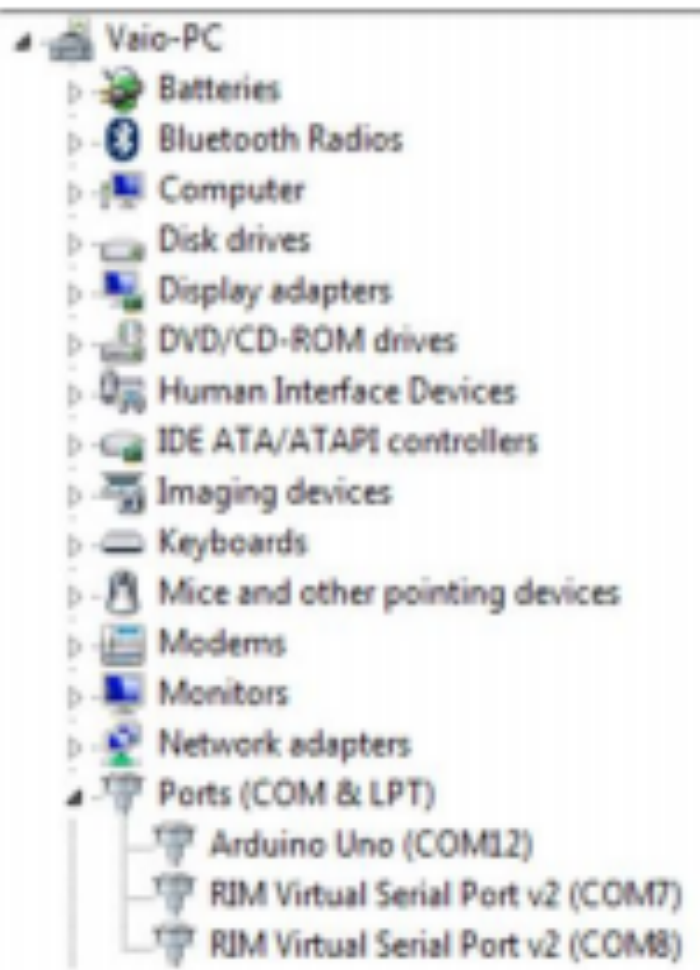

Gambar 6. Koneksi port Arduino

3. Pengujian rangkaian sensor PIR

Pengujian sensor pir bertujuan untuk mengetahui kemampuan sensor dalam mendeteksi keberadaan manusia dari sensor pir, seperti kemudian membuat simulasi dengan seseorang melakukan gerakan, selanjutnya mengamati indikator led pada alat. Jika indikator led menyala maka menandakan bahwa pir bernilai logic 1 dan sebaliknya jika indikator led padam maka menandakan pir logic 0 .
Tabel 3. Koneksi PIR dan Arduino

\begin{tabular}{|c|c|}
\hline PIR sensor & Arduino Pin Control \\
\hline Vout & Pin 2 \\
\hline Vcc & Vcc \\
\hline $\mathrm{GnD}$ & $\mathrm{GnD}$ \\
\hline
\end{tabular}

Pada tabel 3 dapat dilihat bahwa sensor pir di hubungkan ke power supply melalu pin vec dan pin gnd pada arduino yang telah dihubungkan ke breadboard dan pin vout terkoneksi pada pin 2 arduino sebagai counter. Kemudian mengulangi percobaan ini sebanyak sepuluh kali dan mencatat hasilnya pada tabel 4 .

Tabel 4. Hasil Pengujian Sensor PIR

\begin{tabular}{|c|c|c|c|c|c|c|c|c|c|c|}
\hline $\begin{array}{c}\text { Pengujian } \\
\text { ke }\end{array}$ & 1 & 2 & 3 & 4 & 5 & 6 & 7 & 8 & 9 & 10 \\
\hline Led & ON & ON & ON & ON & ON & ON & ON & ON & ON & ON \\
\hline PIR & 1 & 1 & 1 & 1 & 1 & 1 & 1 & 1 & 1 & 1 \\
\hline
\end{tabular}

Hasil pengujian seperti ditunjukan pada tabel 4 menjelaskan bahwa sensor pir yang digunakan dapat bekerja dengan baik. Ketika ada seseorang yang bergerak pada cakupan area sensor pir maka pir akan berlogic 1 dan led indikator pada alat akan menyala. Perubahan resistansi pada pir ini digunakan untuk men-trigger sistem kontroler yang menandakan adanya seseorang yang bergerak.

a. Karakterisasi Sudut Deteksi Sensor

Karakterisasi sudut deteksi sensor diperlukan untuk mengetahui lebar sudut yang dapat dipantau sensor PIR tersebut. Karakterisasi ini dilakukan dengan cara mengukur sudut deteksi sensor, baik dalam arah vertical maupun dalam arah horizontal, terhadap obyek (manusia). Pada arah 
horizontal, obyek ditempatkan pada jarak 1 meter dari sensor, dengan variasi sudut $0^{\circ}, 10^{\circ}, 20^{\circ}, 30^{\circ}$, dan $40^{\circ}$ di samping kiri dan kanan sensor. Pada arah vertikal, obyek ditempatkan pada jarak $50 \mathrm{~cm}$ dari sensor dan dengan variasi sudut $0^{\circ}, 10^{\circ}, 20^{\circ}, 30^{\circ}$, dan $40^{\circ}$ di atas dan bawah bidang horizontal sensor

Tabel 5. Karakterisasi Sudut sensor PIR

\begin{tabular}{|c|l|l|}
\hline \multirow{2}{*}{ Sudut (9) } & \multicolumn{2}{|c|}{ Kemampuan deteksi pada bidang } \\
\cline { 2 - 3 } & Vertikal & Horizontal \\
\hline 0 & Terdeteksi & Terdeteksi \\
\hline 10 & Terdeteksi & Terdeteksi \\
\hline 20 & Terdeteksi & Terdeteksi \\
\hline 30 & Terdeteksi & Terdeteksi \\
\hline 40 & Tidak Terdeteksi & Tidak Terdeteksi \\
\hline-10 & Terdeteksi & Terdeteksi \\
\hline-20 & Terdeteksi & Terdeteksi \\
\hline-30 & Terdeteksi & Terdeteksi \\
\hline 40 & Tidak Terdeteksi & Tidak Terdeteksi \\
\hline
\end{tabular}

Hasil pengujian sudut sensor ditunjukkan pada Tabel 5 Dari table tersebut terlihat bahwa sensor PIR ini mampu mendeteksi obyek hanya dalam rentang sudut $60^{\circ}$, yaitu $30^{\circ}$ ke kanan dan $30^{\mathrm{O}}$ ke kiri sensor pada arah horizontal. Begitu pula arah vertikal, yaitu $30^{\circ} \mathrm{ke}$ atas dan $30^{\circ}$ ke arah bawah bidang horizontal sensor. Pada sudut $40^{\circ}$, baik arah horizontal maupun vertikal sensor tidak lagi mendeteksi objek. Pada sudut yang lebih besar dari $30^{\circ}$ sampai $60^{\circ}$ ke kiri atau ke kanan, sensor hanya dapat mendeteksi obyek pada jarak yang lebih kecil dari satu meter.

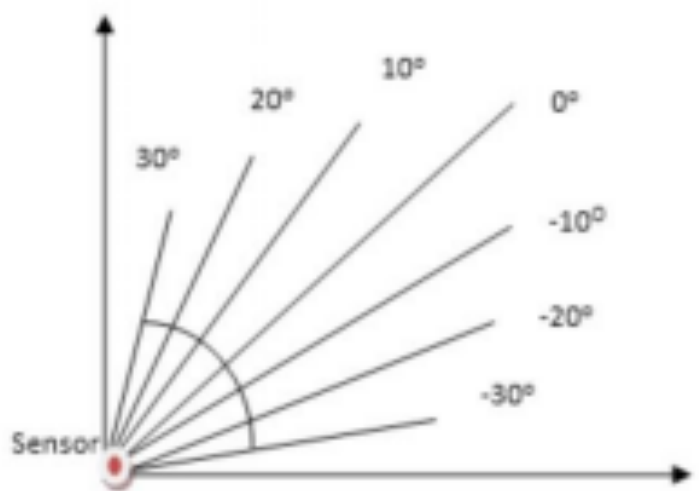

Gambar 7.Tampak atas pengambilan sudut uji sensor

4. Kemampuan jangkauan deteksi sensor pada objek

Pengujian jangkauan deteksi sensor pada objek dilakukan pada area terbuka, pengujian dilakukan pada sudut penerimaan radiasi $0^{\circ}$ (arah radiasi tegak lurus terhadap sensor). Hasil pengukuran jangkauan sensor dapat dilihat pada tabel 6 .

Tabel 7. Jangjauan deteksi sensor

\begin{tabular}{|c|c|}
\hline $\begin{array}{c}\text { Jarak Objek } \\
\text { ke Sensor (m) }\end{array}$ & Kemampuan Deteksi Sensor \\
\hline 1 & Terdeteksi \\
\hline 2 & Terdeteksi \\
\hline 3 & Terdeteksi \\
\hline 4 & Terdeteksi \\
\hline 5 & Terdeteksi \\
\hline 6 & Terdeteksi \\
\hline
\end{tabular}

Hasil pengukuran pada Tabel 7 memperlihatkan bahwa pada sudut $0^{\circ}$ sensor yang digunakan pada penelitian ini mampu mendeteksi keberadaan obyek (manusia) hingga jarak 6 meter.

1. Pengujian daya tembus radiasi inframerah objek terhadap penghalang

Pengujian daya tembus radiasi obyek (manusia) terhadap penghalang dilakukan dengan cara meletakkan berbagai macam penghalang sejauh $10 \mathrm{~cm}$ dari sensor secara 
bergantian di depan sensor. Pengujian ini menggunakan sebuah LED sebagai indikator, dimana apabila sinyal infrared yang dipancarkan oleh objek dapat menembus penghalang maka sensor akan mendeteksi sinyal tersebut sehingga LED akan menyala dan sebaliknya LED tidak akan menyala jika sinyal tidak dapat menembus penghalang.

Tabel 8. Uji daya tembus radiasi inframerah

\begin{tabular}{|c|l|c|}
\hline NO & Jenis Bahan Penghalang & Led Indikator \\
\hline 1 & Kain tipis & Nyala \\
\hline 2 & Kertas Putih & Nyala \\
\hline 3 & Kardus & Tidak nyala \\
\hline 4 & Plastik Hitam (tipis) & Tidak Nyala \\
\hline 5 & Plastik (tupperwarc) & Tidak nyala \\
\hline 6 & Kaca & Tidak nyala \\
\hline 7 & Plat Alumunium & Tidak nyala \\
\hline 8 & Kayu (tebal 2cm) & \\
\hline
\end{tabular}

2. Pengujian Rangkaian LCD

Pengujian rangkaian LCD 16x2 berfungi nantinya untuk menampilkan pesan ataupun tulisan yang dikirim oleh Mikrokontroler. Pada LCD 16 x 2 ini yang berarti 16 baris 2 kolom yang memiliki 16 pin yang mempunyai fungsi masing masing disetiap pinnya. Berikut konfigurasi pin arduino dan lcd dalam pembuatan alat ini :

\section{Tabel 9. Konfigurasi pin ardiono dan}

\section{LCD}

\begin{tabular}{|ll|}
\hline LCD & Arduino \\
\hline 1 & GND \\
\hline 2 & 5 V \\
\hline 4 & PIN 8 \\
5 & GDN \\
6 & PIN 9 \\
7 & - \\
8 & - \\
9 & - \\
10 & - \\
11 & PIN 4 \\
12 & PIN 5 \\
\hline 13 & PIN 6 \\
14 & PIN 7 \\
15 & $5 \mathrm{~V}$ \\
16 & GND \\
\hline
\end{tabular}

3. Impelentasi Rangkaian sistem

Implementasi rangkaian sistem secara keseluruhan dilakukan setelah semua bagian sistem tersebut dihubungkan pada miniatur terlihat pada gambar 8 .

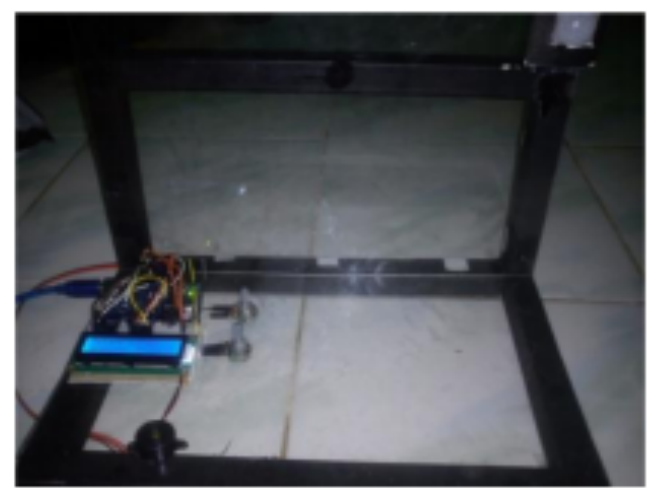

Gambar 8. Rangkaian sistem keseluruahan

Pada Implementasi sistem keseluruhan sistem keamaan ini di uji coba pada sebuah miniatur yang telah di lengkapi dengan sistem keamanan ini.

Implementasi sistem dilakukan pengujian deteksi sensor dengan jarak 6 meter dengan tinggi sensor dari lantai 1 meter dilakukan pada sudut penerimaan radiasi $0^{\circ}$ seperti terlihat pada gambar 9 . 


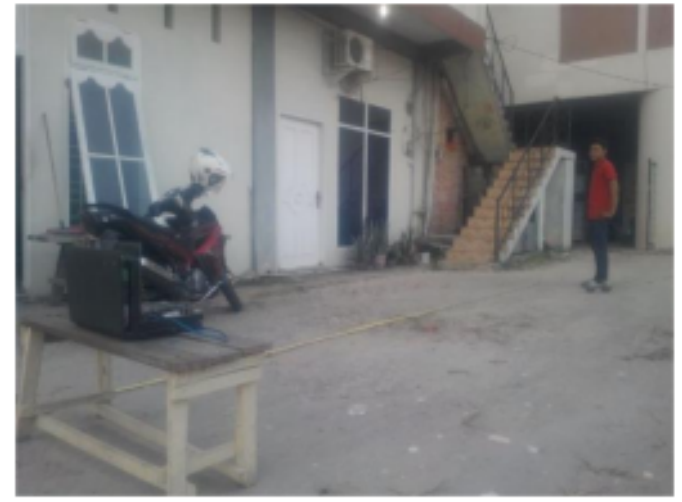

Gambar 9. Uji Sensor jarak 6 meter

Berdasarkan hasil pengujian, sistem keamanan ini telah dapat menginformasikan ada-tidaknya pergerakan pada ruang cakupan sensor. Ketika seseorang berada di dalam cakupan sensor pir, maka pada LCD akan tampil text dengan tulisan "Motion Detected" seperti ditunjukkan pada gambar 4.10 sebaliknya, ketika pergerakan orang didalam ruangan tersebut berakhir, maka LCD akan tampil text dengan tulisan "Motion Ended".

\section{KESIMPULAN}

Dari keseluruhan perancangan sistem keamanan motion detection dapat disimpulkan, yaitu :

1. Sistem ini bekerja dengan baik menggunakan pengendali mikrokontrol arduino dalam pengoperasian sensor PIR mendeteksi gerak dengan memanfaatkan radiasi infra merah yang dipancarkan oleh maklhuk hidup .

2. Lebar rentang sudut pendeteksian yang dapat dilakukan sensor PIR ini adalah $60^{\circ}\left(30^{\circ}\right.$ ke kiri dan $30^{\circ}$ ke kanan). Jarak jangkauan sejauh 6 meter untuk manusia pada posisi $\left(0^{\circ}\right)$ dan 4 meter pada posisi tepi $\left(30^{\circ}\right.$ ke kiri dan $30^{\circ}$ ke kanan dari posisi tengah.
3. sensor PIR yang digunakan pada sistem ini yaitu dapat mendeteksi dengan range sebesar $60^{\circ}$ dengan waktu respon ratarata 2 detik. Sinyal sensor dapat menembus benda-benda tipis seperti plastik, kertas dan kain, tetapi tidak bisa menembus benda yang cukup tebal seperti gabus, papan dengan ketebalan $1 \mathrm{~cm}$.

4. Pada hewan sensor ini juga dapat bekerja, sensor membutuhkan waktu respon yang cukup lama dalam mendeteksi adanya gerak pada hewan seperti kucing.

\section{DAFTAR PUSTAKA}

[1] Andrianto, H. Buku Panduan Pelatihan Mikrokontroler AVR Atmega16, 2008.

[2] Indriyanto,Yogi. Rancang Bangun Pintu Otomatis Dengan Menggunakan Sensor Passive Infrared KC7783R DAN MIKROKONTROLER

AT89S51.Jurnal Ilmiah "FMIPA" UNDIP 2007; 6; 11-14.

[3] Khadir,Abdul. Dasar Pemograman Mikrokontroller Arduino. Jakarta : PT ELEX MEDIA KOMPUTINDO, $2013.2-3$.

[4] Lucky,Yuditia. Mikrokontroler Arduino Uno Untuk Mengontrol Suhu Ruangan Dengan Menggunakan Sensor Suhu, Kipas dan Liquid Crystal Display.Jurnal Ilmiah "Teknik Elektro" Universitas Mercu Buana 2013; 6; 21-25

[5] Muhammad,Zaenal. Sistem Keamanan Rumah Berbasis PIR . Jurnal Fema 2011;1: 12-17. 
[6] Nurcahyo,Sidik. Aplikasi dan Teknik Pemograman Mikrokontroller Avr Atmel, Jakarta : PT ELEX MEDIA KOMPUTINDO, 2013.162-165.

[7] Oktavian I, Martinus, Sugianto. Pembuatan Sistem Otomasi Dispenser Menggunaan Mikrokontroler Arduino Mega 2560. Jurnal Fema 2013; 1:7-3.

[8] Saptaji, H, W. Mudah Belajar Dengan Arduino Uno, Bandung: Penerbit Widya Media,2015. 167 